\section{From Britain}

\author{
V Wright
}

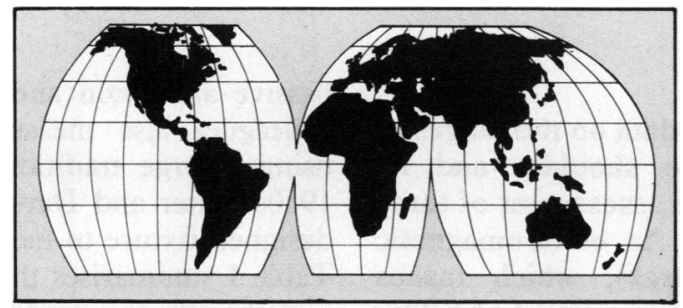

Political considerations have overshadowed research endeavours in the past tumultuous year, during which hospital managers have been pushing institutions into a Trust status despite the opposition of most consultants. The British Society for Rheumatology and the Royal College of Physicians of London have adopted a constructive role in developing the little of the government's plans that is good, particularly an emphasis on audit and resource management. Conferences have been devoted to audit and delineating standards of care despite the doubt that these procedures alter practice. In chronic disease audit seems to be overrated in the absence of well defined end points. There is also a danger that we become so obsessed with measuring things, that we ignore that which cannot be easily recorded numerically and that we do not leave enough time for treatment. Professor Philip Wood (who retired from University service last year to be replaced by $\mathrm{Dr}$ Alan Silman, in the ARC Epidemiology Unit at Manchester) organised a conference to grapple with how to measure the value of what we do. A day conference organised as a joint venture between the British.Society for Rheumatology and the Royal College of Physicians showed the difficulty in defining minimum standards of care for patients with rheumatoid arthritis compared, for instance, with the treatment of urinary tract infections in children. Much bigger general practitioner audiences are being attracted to postgraduate courses because they are being paid to attend. Indeed, the participants are often paid more to attend than the lecturers are to instruct.

A number of distinctions have been achieved by British rheumatologists. The Roussel prize for work on osteoarthritis was won by Professor Dieppe and Dr Bayliss, and Nottingham has the first Roussel fellowship in osteoarthritis offered in the United Kingdom. Dr Doherty and his team are working on synovial fluid changes with exercise in normal people and those with osteoarthritis. The first Roche rheumatology award ( $£ 10000)$ was made to Dr Mark Edbrooke at the Royal Society of Medicine for his contribution to the work of the department of molecular biology at the Clinical Research Centre, Northwick Park (the award reflects the growing interest of Roche world wide in rheumatic diseases). In $1986 \mathrm{Dr}$ Edbrooke joined Dr Woo at the Clinical Research Centre in Harrow, where he has made significant progress in dissecting the intracellular mechanisms by which cytokines control the expression of acute phase protein genes. Edbrooke's work has shown for the first time the involvement of a transcription factor in the induction of an acute phase gene by a cytokine. Dissection of how cytokines produce their pleiotrophic effects on different cells should lead to better drug targeting and should produce more specific treatment in inflammatory conditions such as rheumatoid arthritis. Professor Weatherill's molecular biology group in Oxford is also making strenuous efforts in the rheumatic field.

The Arthritis and Rheumatism Council continues to be prominent in the fields of research and education. A new chair has been established at the University of Glasgow, appropriately coinciding with the 25th anniversary of the Rheumatic Diseases Centre. This was marked by a two day conference at the Royal College of Physicians in Glasgow, hosted by Drs Sturrock and Cappell. Another 25th anniversary was that of the Kennedy Institute, held in the opulence of the Royal Society (a major perk of being elected to this prestigious society is that you can have a parking place in London, and a lesser known one is that the society publishes your biography posthumously). The mantle of director of the institute has passed from the charming shoulders of Professor Helen Muir to the broad ones of Professor R N Maini.

The publication of a third edition of the book on Back Pain, edited by Professor Jayson, reflects the importance of, interest in, and ignorance about this common complaint. The Leeds Bioengineering Group is tackling the problem by assessing the transmissibility of vibrations by the spine. A recent conference of the United Kingdom Informal Group on Human Response to Vibration (hosted in Leeds) was much more clinical than in previous years, including topics such as vibration white finger, repetitive strain injury, vibration and perception, spinal responses, breath sound analysis, bone fracture healing, and workplace safety. Other facets of the British jewel that glinted in the eye of this reviewer were the continuing interest in nonarticular rheumatism and the role of the gut in arthritis, not just because of non-steroidal antiinflammatory drug damage but as a possible portal of entry for infection. The Bristol group has devised a strategy for studying joints with early osteoarthritis, based on the observation that finger and knee changes go together. 